Water Research

Volume 44, Issue 11, June 2010, Pages 3337-3344

\title{
Investigating dissolved air flotation performance with cyanobacterial cells and filaments
}

\author{
Margarida Ribau Teixeira ${ }^{\underline{a}}$, Vânia Sousa ${ }^{\underline{a}}$ and Maria João Rosa $^{\underline{b}}$ \\ ${ }^{a}$ Faculty of Science and Technology, University of Algarve, building 7, Campus de Gambelas, 8005- \\ 139 Faro, Portugal \\ ${ }^{\mathrm{b}}$ Urban Water Division, Department of Hydraulics and Environment, LNEC - National Laboratory for \\ Civil Engineering, Av. Brasil 101, 1700-066 Lisboa, Portugal
}

\begin{abstract}
Dissolved air flotation (DAF) performance with two different naturally occurring cyanobacterial morphologies was investigated with respect to the biomass removal efficiency, the toxin release to water and the coagulant demand by different water background natural organic matter (NOM). Coagulation (C)/Flocculation (F)/DAF bench-scale experiments $\left(2\right.$ min coagulation at $380 \mathrm{~s}^{-1}$ with polyaluminium chloride $\left(0.5-4 \mathrm{mg} / \mathrm{L} \mathrm{Al}_{2} \mathrm{O}_{3}\right.$, the dose depending on the water NOM content $) ; 8 \mathrm{~min}$ flocculation at $70 \mathrm{~s}^{-1} ; 8$ min DAF with 5 bar relative pressure and $8 \%$ pressurised recycle) were performed with single cells of Microcystis aeruginosa and Planktothrix rubescens filaments spiked in synthetic waters with different NOM contents (hydrophobic vs. hydrophilic NOM; moderate (2$3 \mathrm{mgC} / \mathrm{L}) v s$. moderate-high concentration $(c a .6 \mathrm{mgC} / \mathrm{L}))$. For both morphologies, the results show no apparent cyanobacterial damage (since the water quality did not degrade in dissolved microcystins and the removal of intracellular microcystins matched the removal of chlorophyll $a$ ) and high biomass removal efficiencies (93-99\% for cells and 92-98\% for filaments) provided optimal coagulant dose for chlorophyll $a$ removal was ensured. Charge neutralisation by the polyaluminium chloride was the main coagulation mechanism of the $M$. aeruginosa cells and most likely also of the $P$. rubescens filaments. The specific coagulant demand was severely affected by NOM hydrophobicity, hydrophobic NOM (with a specific $\mathrm{UV}_{254 \mathrm{~nm}}$ absorbance, SUVA, above $4 \mathrm{~L} /(\mathrm{m} \mathrm{mgC})$ ) requiring $c a$. the triple of hydrophilic NOM (SUVA below $3 \mathrm{~L} /(\mathrm{m} \mathrm{mgC})$ ), i.e. 0.7 vs. $0.2-0.3 \mathrm{mg} \mathrm{Al}{ }_{2} \mathrm{O}_{3} / \mathrm{mg}$ DOC.
\end{abstract}

Keywords: Dissolved air flotation; Coagulation mechanisms; Natural organic matter; Coagulant demand; Microcystis aeruginosa; Planktothrix rubescens 